Acta vet. scand. $1986,27,296-298$.

Brief Communication

\title{
IMPROVEMENT OF THE TEFLONIZED SLIDES USED IN THE IMMUNOFLUORESCENT ANTIBODY TECHNIQUE
}

The indirect fluorescent antibody (IF) test is often performed on glass slides prepared with smears or tissue sections containing an antigen. It is convenient to have several separate and distinct areas of antigen on the same slide, e.g. to compare dilution steps, and to save time when producing the antigen slides. With this end in view a technique for preparing slides with wells in a thin film of teflon-like compound has been elaborated (Goldman 1968). This technique is useful when a great number of slides need to be prepared in advance, e.g. to test a substantial amount of material. It has, however, not been widely used in serology for Babesia, perhaps because any teflon remaining within the wells is stained with the fluorescent dye, thus creating a potentially disturbing background.

The present paper describes some further technical improvements in the preparation of teflonized slides. The use of a special applicator to make the wells and spread the antigen has made the manual work easier, and counterstaining the teflon layer has made reading the IF-test easier.

The teflonized slides were produced in the following manner. A special applicator was used to put 10 drops of undiluted glycerol onto each of 30 ordinary $26 \times 76 \mathrm{~mm}$ clean glass slides, which had been previously lined up on a plate.

The applicator (Fig. 1) was made of a piece of plastic the same size as the glass slide onto which 10 brass rods were placed at $1.5 \mathrm{~cm}$ intervals. By dipping these rods in a tray (Fig. 1) filled up to a predecided lever, 10 equal drops were transferred to the slide. All slides were then sprayed within 5 min with a teflon spray (Fieson Ltd., England) and subsequently each slide was rinsed under running tap water. This procedure resulted in the creation of 10 wells in the teflon film where the glycerol drops had previously been placed. The wells had a diameter of about $0.5 \mathrm{~cm}$ and about $0.5 \mathrm{~cm}$ of teflonized area between them. This 


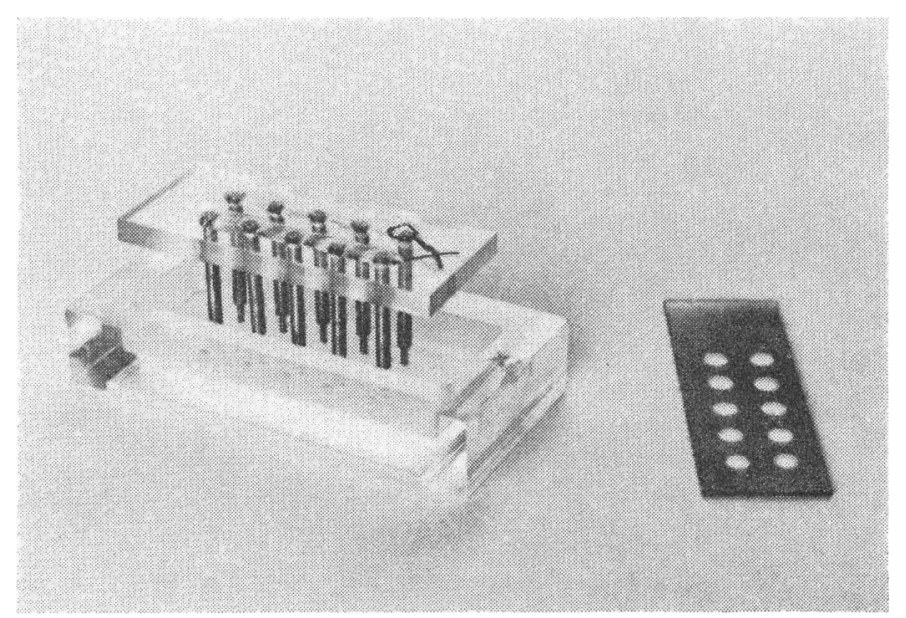

F ig u r e 1. Applicator standing in a tray and to the right a teflonized slide with wells.

prohibited coalescence of adjacent drops of test sera. Morzaria et al. (1977) developed a similar multi-well slide.

The teflon film was then stained by dipping the slides in a $95 \%$ ethanol solution with $1 \%$ filtered gentiana violet for 2 min. The slides were then rinsed with $85 \%$ ethanol and air dried. These stained slides with wells were protected from dust until used. The same applicator described above was then used to spread the antigen smear in the wells.

Using the same applicator both to spread the antigen in the wells and to apply the glycerol drops, facilitated the mass-production of antigen slides. One person was able to produce about 1000 slides per day. Furthermore, the manual work necessary to run the IF-test for Babesia was simplified by using slides with wells in a teflon film, compared to techniques which involve making wells with nailpolish (Goff et al. 1982), spreading antigen with a loop of platin (Leeflang \& Perié 1972) or keeping serum restricted with a piece of mosquito net (Callow et al. 1974).

Staining the teflon film with gentiana violet prohibited any residual teflon within the wells from being stained with FITC by the conjugate. Orientating the slide under the microscope was greatly facilitated by the stained teflon which gave a soft redbrown light under the microscope equipped for reading fluorescence by FITC. 
Commercial slides with wells in a black paint film were much more expensive and the black paint made it difficult to orientate them.

During the last 5 years at least 10,000 IF-tests for diseases such as babesiosis, toxoplasmosis and encephalitozoonosis, have been made using these stained teflonized antigen slides.

\section{ACKNOWLEDGEMENTS}

I wish to express my sincere thanks to Ms Kerstin Candelöf for her skilful technical assistance.

Dan Christensson

The Department of Veterinary Microbiology, Section of Parasitology, Faculty of Veterinary Medicine, University of Agricultural Sciences and Laboratory of Parasitology, National Veterinary Institute, Uppsala, Sweden.

\section{REFERENCES}

Callow, L. L., W. McGregor, R. J. Parker \& R. J. Dagliesh: The immunity of cattle to Babesia argentina after drug sterilisation of infections of varying duration. Aust. vet. J. 1974, 50, 6-11.

Goff, W. L., G. G. Wagner, T. M. Craig \& R. F. Long: The bovine immunoresponse to tick-derived Babesia bovis infection: Serological studies of isolated immunoglobulins. Vet. Parasit. 1982, $11,109-120$.

Goldman, M.: Fluorescent Antibody Methods. Academic Press Inc. Ltd., London 1968, p. 147-149.

Leeflang, P. \& N. M. Perié: Comparative immunofluorescent studies on 4 Babesia species of cattle. Res. Vet. Sci. 1972, 13, 342-346.

Morzaria, S. P., D. W. Brocklesby \& D. L. Haradine: Evaluation of the indirect fluorescent antibody test for Babesia major and Theileria mutans in Britain. Vet. Rec. 1977, 100, 484-487.

(Received July 4, 1986).

Reprints may be requested from: Dan Christensson, the National Veterinary Institute, P. O. Box 7073, S-750 07 Uppsala, Sweden. 